\title{
Characterising and
}

\section{communicating the potential hazard posed by PTEs in indoor dusts from schools across Lagos, Nigeria $\underline{\text { Abimbola O Famuyiwa }}{ }^{1}$ and Jane Entwistle ${ }^{2}$}

${ }^{1}$ Department of Science Laboratory Technology, Moshood Abiola Polytechnic, Abeokuta Ogun Nigeria

${ }^{2}$ Department of Geography and Environmental Sciences, Northumbria University, Newcastle-upon-tyne, UK

(*Correspondence: abimbola.famuyiwa@gmail.com)

Ambient and indoor air pollution results in an estimated 7 million premature deaths globally each year, representing a major contemporary public health challenge, but one poorly quantified from a toxicological and source perspective. Classroom dust samples were collected from 40 locations across Lagos, Nigeria in June 2019. The aim of the study was to assess the potential hazard posed by PTE in indoor dusts and to develop a suitable risk communication strategy to inform and educate the public, promoting environmental health literacy. Levels of PTE in indoor dusts was assessed using Energy Dispersive X-ray Fluorescence spectrometryy. Oral bioaccessibility testing was also performed on the dust samples to determine the fraction available for absorption in the human gastrointestinal tract. Source apportionment studies using factor analysis and cluster analysis suggests concentrations of $\mathrm{As}, \mathrm{Fe}, \mathrm{Ni}$ and $\mathrm{V}$ are predominantly influenced by lithogenic factors, while $\mathrm{Cd}, \mathrm{Cu}, \mathrm{Pb}$ and $\mathrm{Zn}$ principally originate from anthropogenic sources. Barium and $\mathrm{Cr}$ appeared to be emanating from mixed sources. Oral bioaccessiblity studies confirmed that the assumption of $100 \%$ bioavailability based on pseudototal or total concentrations would overestimate the exposure risk of $\mathrm{Cu}$ (by $36 \%$ ), As (by 37\%), Pb (by 48\%), Ba (by 48\%) and $\mathrm{Mn}$ (by 57\%). Zinc was the most bioaccessible PTE (mean of $88 \%$ ), Human health risk assessment findings however indicated exposures to all of the PTE investigated to be within acceptable risk levels. As part of the wider risk communication strategy each school received a bespoke report and setting recommendations to minimise exposure to PTE in the indoor environment. The study is contributing data to the global dust study at maymyenvironment.com. 